\title{
Arts Practice: Chaos, Order and Disequilibrium
}

\author{
Miik Green, Curtin University of Technology, Western Australia
}

\begin{abstract}
This paper explores notions of chance and chaos in arts practice, aligning the author's artistic practice with the Deleuzian concept of rendering 'unseen forces visible'. The visual artist, through studio process, can reveal unseen forces similar to those that exist in the biological world. This research references the fields of art and science, comparing the art studio to that of the science laboratory, where an artist approaches materials as an industrial chemist might, combining matter in disequilibrium. Forms representative of diatoms, pollen and radiolaria manifest in this process, appearing as encapsulated experiments. By capturing, suspending, or pausing these material interactions, one can visualise these structures. The paintings referenced here seek to unconceal through an active disequilibrium, where pigments separate, resin seals and tension reveals. The light that is refracted and reflected through and by this metamorphosis changes the nature of the materials: inks and resin turn from liquid to solid, darkness to light.
\end{abstract}

Keywords: Disequilibrium, Chaos, Order, Resistance, Arts Practice

Nature must be 'put to the torture' and made to yield its reluctant secrets to the astute investigator Sir Francis Bacon (1561 - 1626)

\section{Unseen Forces}

$\mathbf{T}$ This paper encompasses the fields of art and science, but is directed specifically at one instance of studio-based, contemporary visual arts practice. From a scientific perspective, forces of chaos and order can be seen as operating together while in a mutually-resistant relationship. In studio practice, the visual artist can attempt to visualise these concepts by combining immiscible materials. Similar forms are seen in the intricacies of select biological microforms. In creating these unlike combinations, the artist's working methods resembles those of the industrial chemist - in manipulating material to reveal abstract concepts. According to Gilles Deleuze, the artist's mandate should be to reveal these invisible forces - in this paper, through resistant tension. This disequilibrium can be evidenced in the studio (material experimentation) to action in arts practice (the artist's struggle to antagonism). We can experience this disequilibrious action by mixing heterogeneous material combinations such as oil and water. Such resistance produces forms diverse in appearance, from pollen, diatoms and radiolaria, to cellular organisms.

The research introduces the concept of disequilibrium to the relationships between creative production, cross-disciplinary investigation and arts research. It proposes the visual artist should maintain an awareness of this inherent equilibrium, where this cognisance can alter the approach to these environments. Where equilibrium exists in the formation of natural structures, aligning with Deleuzian notion of unseen forces (and their unveiling through creative production), I seek to privilege the conflict, resistance and opposition that arise from creative activity as beneficial to arts practice. Art has the ability to reveal: that which may have been previously hidden, either invisible or concealed. In his book on the painter Francis Bacon, titled The Logic of Sensation, Deleuze speaks of revealing these invisible forces. Borrowing a Paul Klee quote, he refers to painting as something that should render visible instead of rendering the visible' (Deleuze, G. 1981, 48). As a visual artist, I concur: eliciting these forces through the visual arts is significant. But can this premise be taken further? Can these forces be captured whilst in a state of movement as opposed to stasis - or both? And how does the visual artist then approach the task of visualising these abstract concepts? 


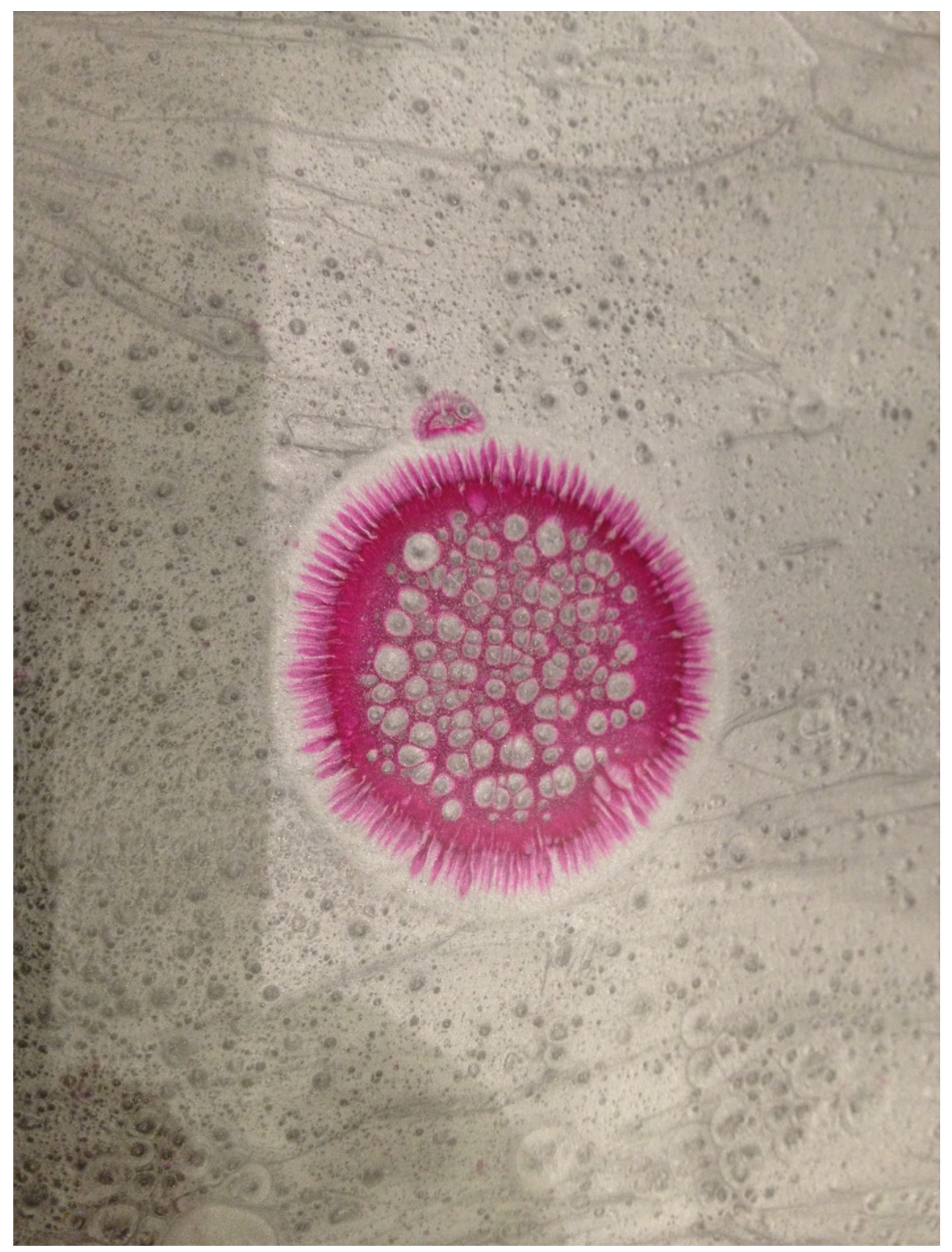

Fig 1: Xylem series: Excelsa 11 (detail). Mixed media on aluminium. 45 x 45cm, 2013. CMiik Green, photo courtesy the artist.

An early model of this visualisation dates back to 1904, when 'Kunstformen der Natur' was first released (Haekel 1974). This publication contained numerous plates of microorganisms, sketched by the biologist Ernst Haekel. Forms that were documented varied from polyps and algae to diatoms and radiolaria. By translating these forms, Haekel was able to reveal to the viewer something previously hidden, available only to scholars of that period (Haekel, E. 1974, introduction). Haekel rendered these scientific structures artistically - and through this process revealed them to a wider public - as aesthetic forms. In contemporary art, the visual artist also participates in this translation, and subsequent means of revealment. My work, (see Fig 1) shows the emergent radiolarian-like structure, a result of this unlike material combination. This process has formed a structure so realistic that it appears as a photographic representation of a microform or an image of a cell's interior. As a detail from a painting, it is neither - it is an artwork visualised through disequilibrium: part chaos, part order, like Haekel's forms.

Radiolaria are microscopic sea-forms: marine protozoa. Similarly intricate, skeletal and organic, their representations materialise when I inject coloured ink into catalysing layers of resin. They bloom, bubble, separating in striating sections. As the artist and maker, I view these interactions in real-time, as if watching the separation of living cells through a microscope. The processes of art seem to align at 
this stage with the mechanisms of life, between materials and mitosis. At later stages of the catalysing process, the resin becomes gelatinous, plastic-like, and resists the intrusion of ink. During earlier stages, shapes develop homogeneously as the molecular bonds are loose and liquid. The pigments disperse within the layers creating blurry or ambiguous configurations as opposed to the above image, with its distinct separations.

In exploring these structures representative of the scientific and aesthetic, I see convergence here (in the fields of art and science) as a dialogic clash, existing together/apart. James Elkins opens in Aesthetics and the Two Cultures with: 'I have never been convinced that science has much to do with painting - or with art in general' (Elkins, J. 2008? 34), likening a dialogue between art and science to a drunken conversation. In contrast, Miller sees a future where art and science will be indistinguishable from one another, a third space or common frontier he loosely refers to in Two Worlds as One (Miller, 2001). I neither agree with Elkins or Miller here, approaching this relationship as one of dialogism, where two fields co-exist in resistance - where the artist and scientist approach similar ideas discretely. It is a concept similar to the production of these forms: emerging via latent tension, transformation is seen here in opposition. It is unveiled in tension.

Deleuze likens this unveiling process in painting as trying to 'attempt to render forces that are not themselves visible’ (Deleuze, G. 1981, 48). Approaching this from an arts and science perspective, writer Arthur Miller offers the German term Anschauung as 'visual imagery abstracted from phenomena we have witnessed with our senses' (Miller, A. 2001, 47). Miller posits that this mode of seeing developed Einstein's intuition as a scientist, stating that he 'benefited greatly from the emphasis at Aarau on the power of visual understanding, of Anschauung' (Miller, A. 2001, 48). Miller and Deleuze briefly cross here in terms of unveiling: where Miller refers to Einstein's ability to visualise, to see beyond scientific theory, the artist's challenge by Deleuze is in a similar vein - in rendering visible what may be hidden, invisible or unknown.

Heidegger furthers this in terms of unconcealment, where forms are concealed and are able to be revealed from concealment and into transformation. He states: 'The challenging happens in that the energy concealed in nature is unlocked, what is unlocked is transformed...' (Heidegger M. 1982, 16). As a visual artist, I am interested in the transformative processes of resistant materials where this unconcealing fluctuates between scientific study and artistic investigation.

Artist Tony Cragg, (a sculptor who originally trained as a scientist) states that science lacks 'perceivable images' for its theories, asserting that the visual arts are 'an important supplement and expansion of the sciences' (Cragg, T. 1999, 31). In agreement with Cragg, I would add that the sciences would be assisted by this mode of 'seeing' Miller identifies. Kant speaks of the 'logical representation of the purposiveness of nature' (Kant, I. 1914, 22), and closer in revelatory terms to scientific notions of representation. Similar abstract concepts are contained in my practice, yet align closer to his notion of an 'aesthetic representation of the purposiveness of nature' (Kant, I. 1914, 19) in appearance, where forms and structures are emerge from resistant materials. In Fig 2, these interventions are sealed within layers of resin, and cell-like striations have bloomed within the surface of the painting. The detail captures movement, growth and this purposiveness, yet it reveals through concealement - liquid confined to solidity, resistance restrained.

I find these ideas are better expressed in the form of poetry - some of the above ideas are embodied in this poem, entitled Asphyxia:

Pulled, from grey abyss, excised into lightness

pulsing and still, against the will.

Where tendrils entrenched -

stretched, where puckering

suckers left marks:

stress marks, the burst vessels

vesicles, spent and submerged now.

No longer clinging,

The life fleeting

not beating ... 
Where veins pump coagulant - and circulation slows,

in the suffocating ooze.

the heaviness of the instruments,

the deadening of sound,

the dull pumping.

While whirring attempts to revive carry on

... around ...

situated in a space, one

between survive and revive.

between

In display and on display

Miik Green, 2014

\section{Paint, Plane and Pigment}

Deleuze likens the act of painting to the artist's engagement in visualising chaos and order, stating: 'Where painters differ is in their manner of embracing this nonfigurative chaos, and in their evaluation of the pictorial order to come, and the relation of this order with this chaos' (Deleuze, G. 1981, 84). My studio processes alternate between these two concepts, where disequilibrium is the active factor in transformation. For example, there is order in approaching my paintings: measuring liquids, separating pigments and creating parameters of a set format, all within a two-dimensional picture plane. Yet this act of resistant combination - pouring liquids together on aluminium enabling the materials to interact independently - is chaotic. Heterodox combinations result in materials physically reacting, rejecting or resisting one another, where pigment allows the process to be better visualised, as clarity emerges through colour separation. 


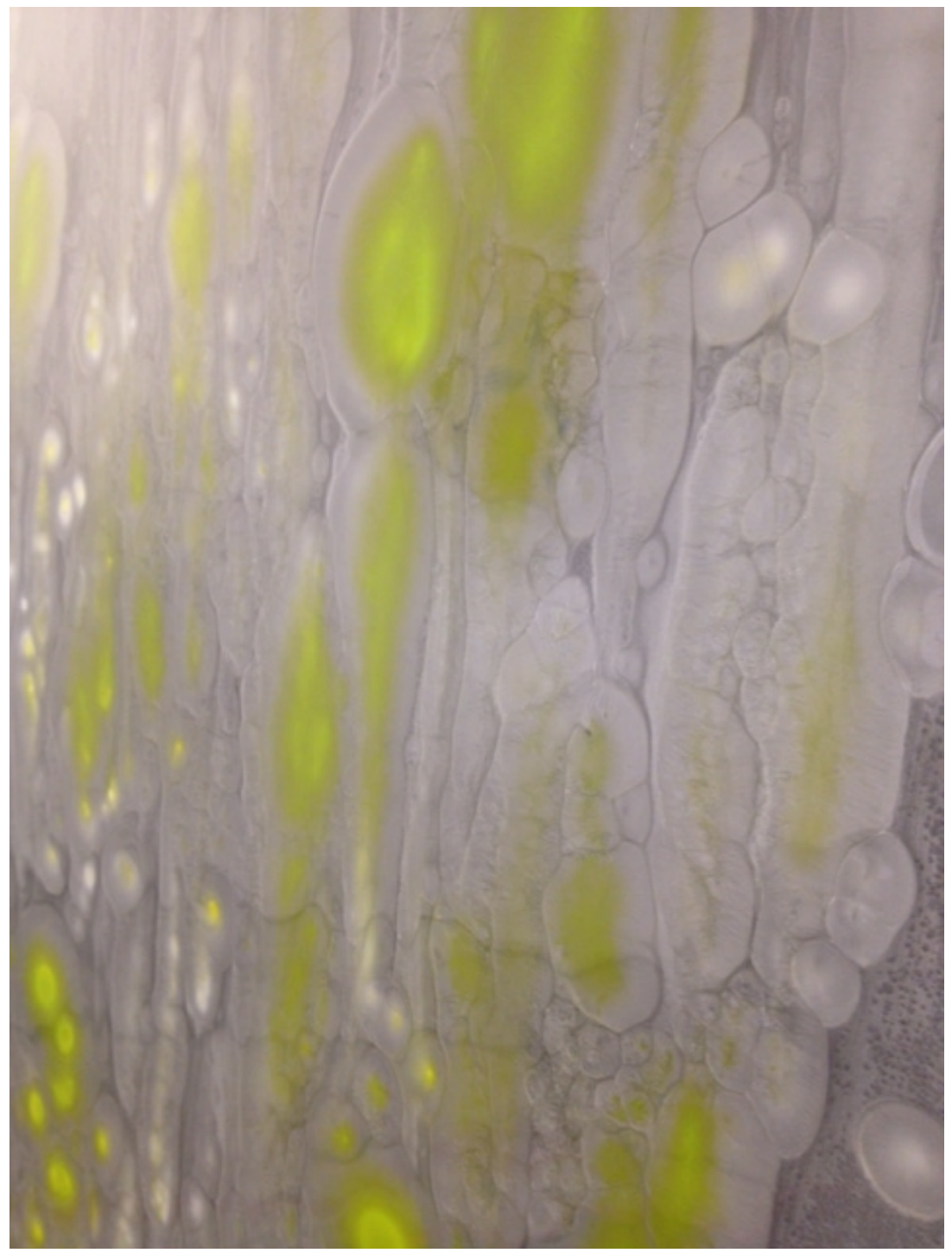

Fig 2: Xylem series: Meiosis (detail). Mixed media on aluminium. 107 x 107cm, 2013. CMiik Green, photo courtesy the artist.

The works are large-scale, non-representative panels that reference a natural (yet unnatural) microworld. Resins, inks, dyes and industrial chemicals are abstractly applied to an aluminium 'canvas'. These products are poured, layered or dragged together across the panel and combined in viscous consistency. Surfaces and finishes are highly reflective, containing a unique physicality due to the multiple layers of applied resin. Colour is a pivotal element, as contrasting and merging pigments appear to struggle in suspension. The dimension $(200 \times 200 \mathrm{~cm})$ aims to fill the visual field of the viewer, resulting in an immersive experience. The surface plane becomes indiscernible, creating tension through movement and stasis.

The disequilibrium that relates to the idea of unseen force can be applicable to arts practice. In describing the vibrant colour fields of Anish Kapoor's works, Rosa Martinez describes this effect as:

'...the phenomenology of the connection between the material and the spiritual, between the mutable and the permanent, between the visible and the mensurable and the invisible and the incommensurable, between the masculine and feminine, is part of the alchemist's quest for the coincidentia oppositorum in which the heart is the retort where these opposites are dissolved' (Martinez 2008, 40)

In Eastern philosophy the complimentary nature of opposites is pivotal to wellbeing, similar to the Taoist worldview, implicit in the yin yang symbol. In Western philosophy the term 'coincidentia oppositorum' translates as a 'coincidence of opposites', a neo-Platonic term that also draws on origins 
from the early Greek philosopher Heraclitus. Working from this premise, Heraclitus proposed that all things contain an opposite, and it is from this function that meaning is also derived. The concept of heat, for example, cannot exist without the corresponding notion of cool. Utilising this view, polarity is present in all things, from atoms to mountains, the physical to the spiritual.

This idea of unlike combination and resistance forms the theoretical component of my practice, where the tensional relationships between chaos and order negotiate equilibrium. This resistance can also be a necessary process in producing these unpredictable forms: this idea of resistance or conflict also opens a wider dialogue that includes the notions of the artist's struggle or of working collaboratively across disciplines. Is the struggle a full-time artist often faces necessary to produce groundbreaking work? When one is forced to work in uncomfortable situations or use alternative methods due to less than ideal circumstances, artwork may evolve in an exceptional, albeit unplanned, manner.

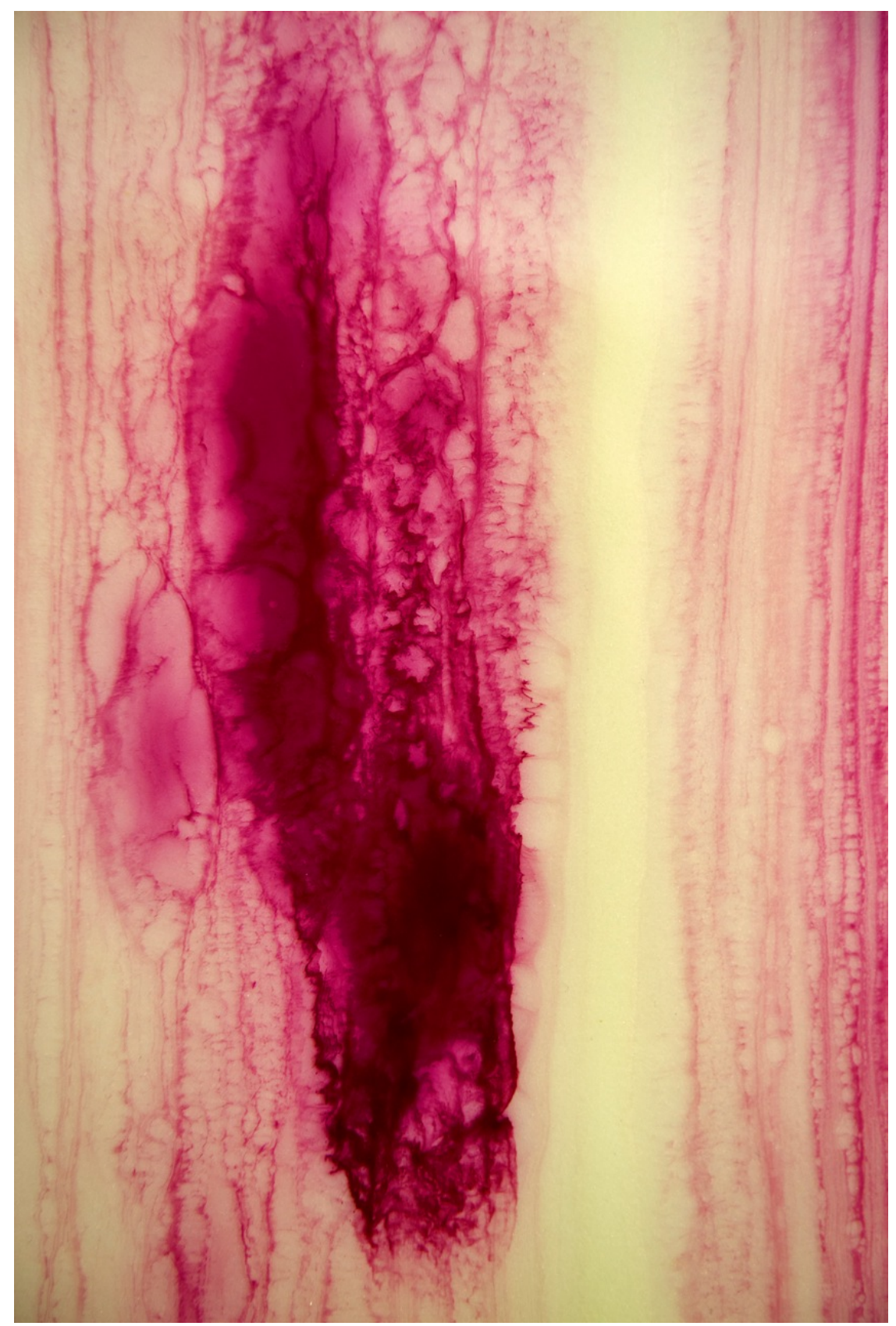

Fig 3: Xylem series: Haplostele 13 (detail). Mixed media on aluminium. 107 x 107cm @Miik Green. Photo courtesy Jody D’Arcy/Jo Carmichael, 2013. 
Shifting this equilibrium may produce force that can equate to discomfort on one level or conflict on another. The opening quote in this paper from Sir Francis Bacon, the English philosopher and scientist, refers not only to revelation in nature, but to the process: one he describes as 'torture'. While Sir Francis would not be sympathetic to the propositions here, notably those promoting chance or inviting instability, he actively pursued a similar unconcealment in nature. Art and science are both interested in the revealing of abstract concepts, and while their methodologies may differ, in arts practice I see this unveiling through disequilibrium. It is through this active tension these microcosmlike forms appear, budding and efflorescing within the paintings. Figure 3, (Haplostele 13 from the Xylem series) shows fleshy, pulpy forms that are as ambiguous as a scan of the body's interior, cellular staining or dendritic geography. Resistance is evidenced as the colours separate, forcing veining structures that creep throughout the large expanses of colour.

Musician Ben Folds notes: 'Most good art comes from some turmoil, from someone trying to come to some equilibrium, or come up and get a breath'. Folds recognises the necessity of dialogic force in his creative production, the action being one of disequilibrium. This concept can also apply to interdisciplinary environments, combining unlike resources. Working across disciplines can stretch a practice, as one is forced to confront methods and processes outside or across traditional boundaries.

\section{Disequilibrium and Cyclicity}

The working method models the artist's studio on that of a science laboratory. Using the lab as an example, the scientist or chemist studies glass plates that seal bio-items like blood cells or tissue. As the artist, I substitute resin for glass plates and inject matter (synthetic materials such as inks, acrylics, polyurethanes and solvents) into the layers as they catalyse. The resin here becomes a revealing agent, capturing liquid interactions in solid state. The structures 'bloom', sealed as if for further examination as the resin hardens. Where the scientist utilises a microscope in probing the minutiae, details of the structures I produce are visible to the human eye, appearing like magnified cellular stratum - displaying their form for analysis.

These patterns develop like small, encapsulated experiments. By suspending or pausing these visual interactions, I am able to record a 'moment' similar to that in which the photographer instantaneously captures an image on the camera. These forms are created through heterogeneous catalysis, the scientific process in which this transformation occurs, a term common in organic chemistry. The forms within the hardened, clear resin are now sealed in a solid that has become mirror or glass-like. The light that is refracted and reflected through this metamorphosis is what affects the materiality of the pigments, where inks and resin turn from liquid to solid, alternating between atmospheres and atoms.

Organisms, cells and atoms are separate entities, and operate discretely to form the cohesive, united functions found in living organisms. Ultimately they break down, forming another cycle, and materialise again as other entities. From life to death and beyond, these are the unseen, chaotic cogs within a highly organised system - one in constant dialogism. Unique combinations permeate artist Olafur Eliasson's work, described by Madeleine Grynsztejn as being 'built around a series of coexisting and incommensurate oppositions' (Grynsztejn, M. 2002, 92). Disparate elements co-exist in Eliasson's work, they embody unlike tension as discrete segments vie for primacy. This dialogism is evidenced in my paintings as a material struggle: where pigments separate and suck in disarray, revealed under stress. They form part of a greater structure, a cycle that seals to reveal and reveals to suspend. It is one that rotates, revolves, and repeats - from the cosmic to the cellular. 


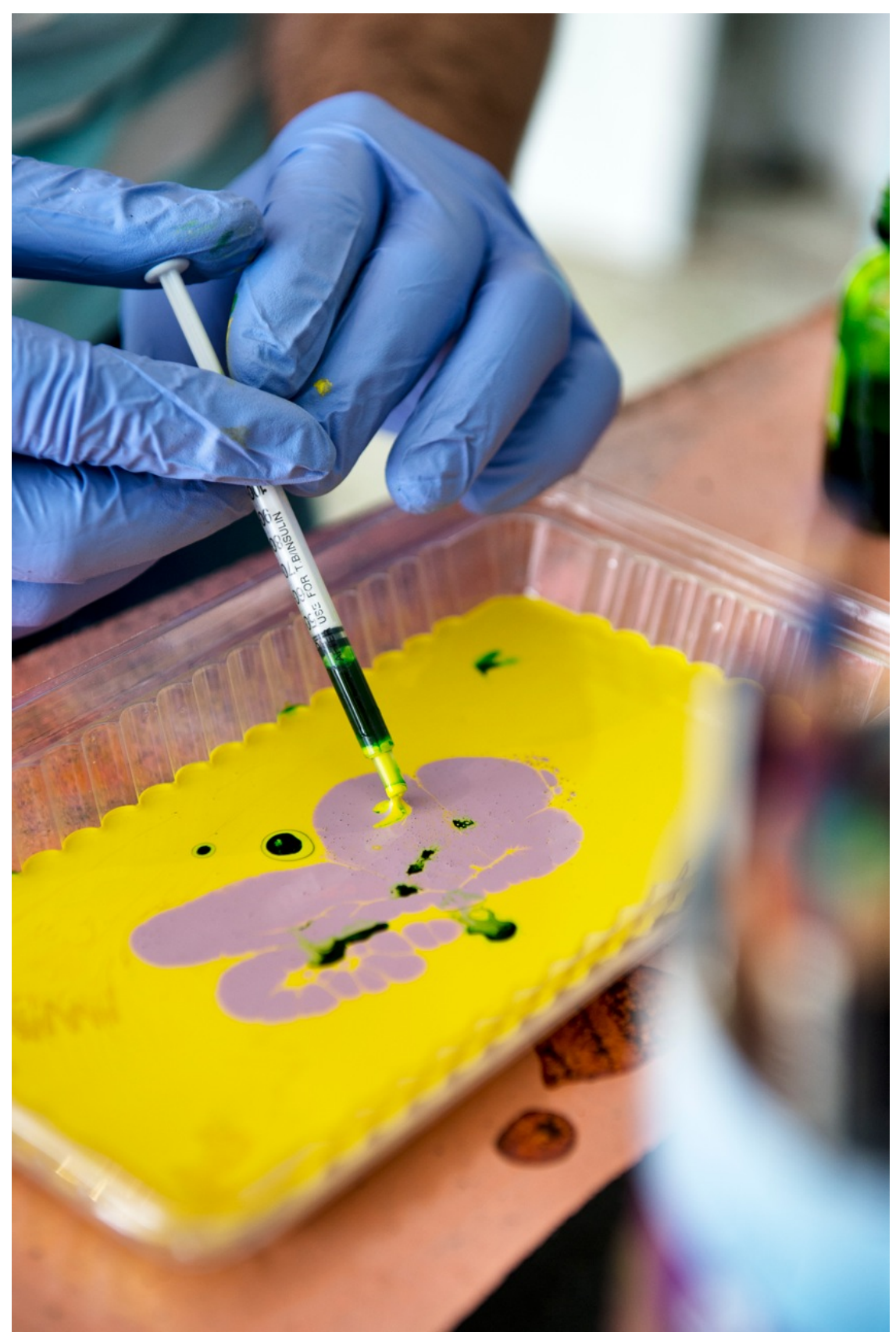

Fig 4: Material testing in the studio @Miik Green. Photo courtesy Jody D’Arcy/Jo Carmichael, 2013.

It is through this mutual elaboration that a new dialogue emerges, engaging with a process that combines conflict and resistance. It is one evidenced in an entity composed of opposing and unique elements. When these disharmonious elements amalgamate, they enter a struggle necessary for transformation. The method behind this union could be applied to fields as diverse as dance or music, where a focus on fluidity or harmony may be seen as desirable - this approach values the unplanned, the incongruent - even opposing in methodology. In my practice, I operate alongside architects, scientists and most recently a palynologist. These relationships have yielded bodies of work that have altered the trajectory of my practice. As arts practitioners, how do we negotiate disequilibrium in interdisciplinary engagement? Does it matter how we approach these borders, and do the boundaries of our fields factor in these decisions?

Many of my works require examination - and re-examination where subtle light interaction highlights areas I may have previously glossed over. As an active participant in this process, I am able to see these interactions, or as Elkins better puts 'once you start seeing them, the world-which can look so dull, so empty of interest-will gather before your eyes and become thick with meaning' 
(Elkins 2000, 13). This discourse opens a new approach to the field of arts practice, in recognising the disequilibrious: from studio application to methodologies in arts practice. It is a discussion that permits the unpredictable, unplanned or unstable, seeing the value of action-towards-equilibrium. It sees the permeable in the impervious, the fleeting in the permanent and the animated in the stationary. In allowing for heterogeneous intervention, an unveiling process occurs, where action is found in disequilibrium: between writing and making, research and production, a rendering visible. It is awareness of this tension and the corresponding struggle, which reveals a cyclic nature, the stasis-influx of arts practice: it is the generative activity either side of equilibrium.

\section{Acknowledgements}

Dr Michael Seats, Professor John Teschendorff, Dr Ioannis Michaloudis, Dr Oron Catts and Chris Malajczuk.

\section{REFERENCES}

Cragg, Tony. 1985. Exhibition Catalogue Société des expositions du Palais des Beaux-Arts de Bruxelles, 20 june-28 July, 1985. Paris: ARC-Musée d'art moderne.

Deleuze, Gilles. 1981. Francis Bacon: The Logic of Sensation.

Minnesota: University of Minnesota Press.

Elkins, James. 2009. "Aesthetics and the Two Cultures: Why Art and Science Should Be Allowed to Go Their Separate Ways”. In Rediscovering Aesthetics: Transdisciplinary Voices from Art History, Philosophy, and Art Practice. F. Halsall, J. Jansen and T. O’Connor ed. Palo Alto: Stanford University Press.

Elkins, James. 2000. How To Use Your Eyes. New York: Routledge.

Grynsztejn, Madeleine, Daniel Birnbaum and Michael Speaks. 2002. Olafur Eliasson. London: Phaidon Press Ltd.

Haekel, Ernst. 1974. Artforms In Nature. New York: Dover Publications Inc.

Heidegger, Martin and William Lovitt. 1982. The Question Concerning Technology and Other Essays. New York: Harper Collins.

Kant, Immanuel. 1914 (reprinted 2005). Critique of Judgement. New York: Dover Publications.

Miller, Arthur. 2001. Einstein, Picasso: Space, Time, and the Beauty That Causes Havoc. New York: Basic Books.

Martinez, Rosa. 2009. Anish Kapoor: Islamic Mirror. Spain: Libecrom Publications. 


\section{ABOUT THE AUTHOR}

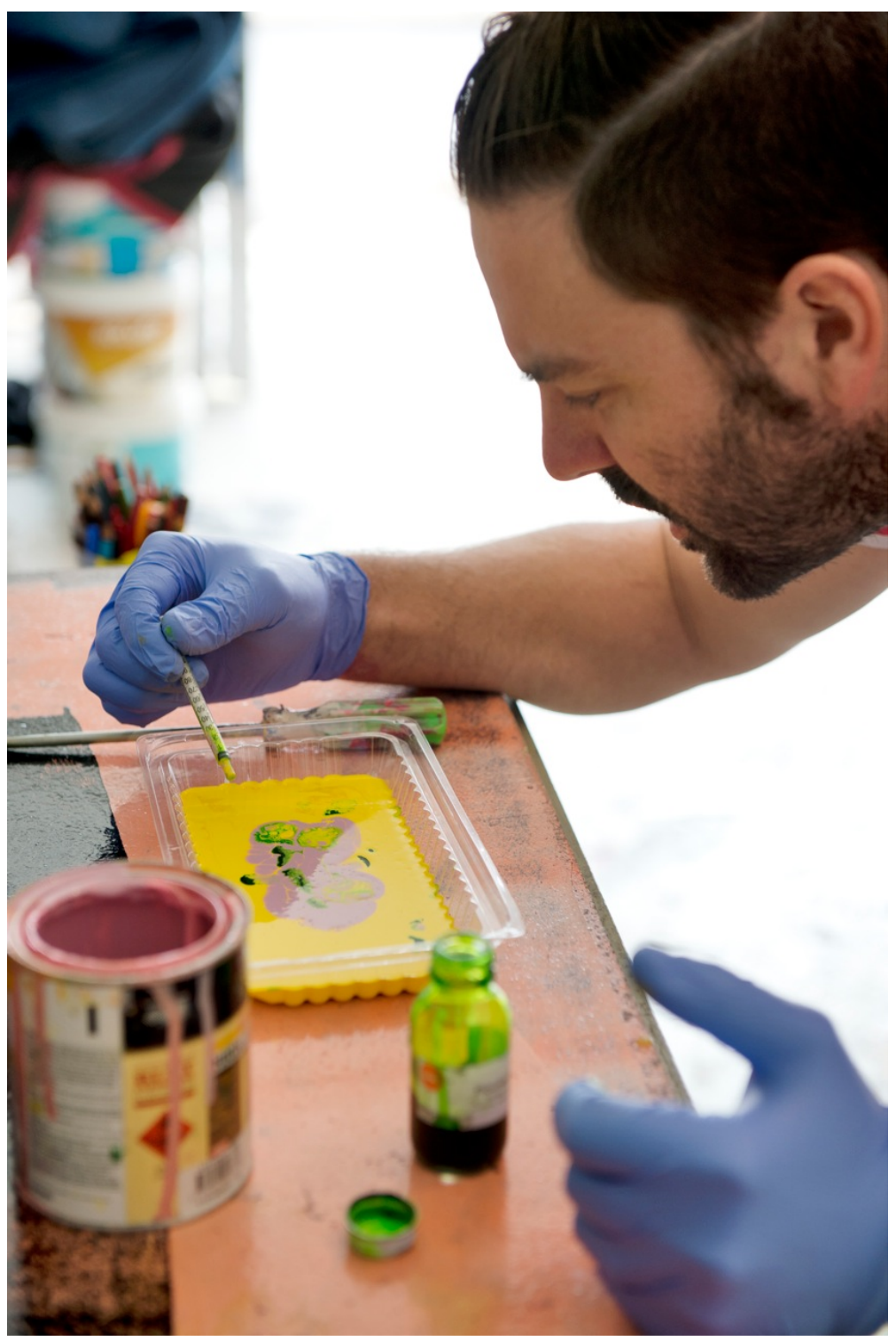

Fig 5: The artist testing materials @Miik Green. Photo courtesy Jody D’Arcy/Jo Carmichael, 2013.

Author: Miik Green is a multidisciplinary visual artist living in Perth, Western Australia. Green draws his inspiration from the microscopic aspects of nature, and is currently involved in cross-disciplinary artistic collaborations that integrate the fields of science, mathematics, chemistry and physics. The strength of his practice lies in his ability to translate microforms such as fungi, coral, seed pods, diatoms, blood cells and radiolarian, into paintings and sculptural pieces, while preserving the integrity of the original form.

Green is a PhD candidate at Curtin University and recipient of an Australian Postgraduate Award for research excellence. He is represented throughout Australia by Flinders Lane Gallery (Melbourne) and Linton \& Kay Contemporary (Perth). Green has completed a Bachelor of Arts (Hons, 1st Class) through Curtin University, a Bachelor of Visual Arts, Painting at Edith Cowan University in Western Australia and an Advanced Diploma of Industrial Design through the WA School of Art and Design. 